\title{
On the Automatic Learning Ability of Spanish Learners under the Perspective of English-Spanish Language Transfer
}

\author{
Huiling Yuan \\ School of Intercultural Studies, Jiangxi Normal University \\ Nanchang 330022, Jiangxi, China \\ E-mail:yh10807@gmail.com
}

$\begin{array}{lcc}\text { Received: May 15, } 2011 & \text { Accepted: May 30,2011 Published: October 1, } 2011 \\ \text { doi:10.5539/ass.v7n10p122 } & \text { URL: http://dx.doi.org/10.5539/ass.v7n10p122 }\end{array}$

Foundation Item: "Study of Accelerating Establishment of Spanish Undergraduate Program in Jiangxi" of the "Twelfth Five-Year Plan" of Jiangxi Education Science (Project No: 10YB318)

\begin{abstract}
Both English and Spanish belong to inflectional languages and phonetic scripts, for there exists obvious positive and negative transfer between these two languages in terms of pronunciation, vocabulary and grammar. The inscape of automatic learning ability comprises four first-class indexes and several second-class indexes. To establish correct views of language learning, realize the transfer of cognitive structure, strengthen the meta-cognitive training, and change the traditional role of teachers are effective strategies to correctly employ the transfer effects of English upon Spanish learning and to foster and enhance the learner's automatic learning ability.
\end{abstract}

Keywords: Language transfer theory, English, Spanish, Automatic learning ability

With increasing frequent interaction between China and Spanish speaking countries, demands of the society on Spanish talents is on the increase and there are more and more Spanish learners. Considering the kinship of language, English and Spanish both fall within the Indo-European scope, for great relevance exists between these two languages in terms of pronunciation, vocabulary and grammar. This paper discusses the basic strategies to strengthen automatic learning ability of Spanish learners based on the "blood relationship" between the two languages and on the basis of analyzing with emphasis English transfer in learning of Spanish, according to the basic fact that English is the first foreign language of a large majority of Spanish learners.

\section{Explanation of the connotation of linguistic transfer theory}

Different disciplines have different comprehensions in the word "transfer", and this paper explains this expression from a linguistic perspective. According to the Linguist Bußmann Hadumod, "Transfer --- a psychological term, represents facilitation to or influences of a behavioral pattern that has already been acquired upon a behavioral pattern that is going to be acquired. In linguistics, this term represents influences of characteristics of the mother tongue upon acquisition of a foreign language, which have both positive influences (if the two languages are similar) and negative influences (interference)." (Bußmann Hadumod, 2003) Ellis defined "transfer" as a sort of "hypothesis that learning of Task A would affect learning of Task B, and if "Task A and Task B" are replaced with the first language and the second language, this is transfer of language. (Yu Liming, 2004) Odlin gave the most authoritative definition to "transfer of language". According to him, transfer of language did not only refer to influences of the mother tongue of language learners as in traditional studies of transfer, but also referred to influences of knowledge of any other language that had been acquired or had not been totally acquired by language learners upon a new language acquisition. He emphasized that transfer of language was a sort of "cross-linguistic influence". (Odlin, T., 2001)

As for conditions for occurrence of the phenomenon of transfer, the representatives of the earlier transfer theories, "common element theory", E.L.Thorndike and R. S. Woodworth pointed out, "Only when two learning contexts have similar elements, transfer between the two languages can occur. And the more similar elements the two contexts have, the larger is the transfer." Manifestation means of transfer of language includes three types, 
namely, positive transfer and negative transfer, interlingual transfer and intralingual transfer, and communicative transfer and learning transfer. Thus, from the definition of transfer of language, it is not difficult to find that, with continuous changes in knowledge of transfer of language, people come to realize that transfer of language is not merely a sort of linguistic phenomenon, but also a sort of psychological process, more a sort of learning strategy in which new language is developed through a known language.

\section{The phenomenon of transfer of language between English and Spanish}

English and Spanish both belong to inflectional languages and phonetic scripts. Considering the "kinship" between English and Spanish and the English foundation that Spanish learners have already possessed, it can be found through a comparative analysis of the two languages that, obvious transfer of language exists between English and Spanish in terms of pronunciation, vocabulary and grammatical structure. Owing to limited length of the paper, we here only give explanation from the positive transfer and negative transfer by selecting typical cases in specific content of each type of transfer.

\subsection{Transfer in terms of pronunciation}

Mostly, transfer between English and Spanish in terms of pronunciation is reflected as negative transfer, which means that existing English knowledge among Spanish learners who only have good English foundation is not only unable to facilitate their learning of Spanish, but, on the contrary, may impede learning of new language knowledge in their learning of Spanish to a certain extent. As is well known, most Spanish characters are derived from Latin letters. Ever since 1994 when Spanish Royal Academy decided to no longer regard "ch and 1l" as independent letters, Spanish letters have been constituted by the 26 English letters together with ñ. Similar with English, Spanish also belongs to inflectional language, but its suffix inflection has been greatly simplified after evolution for a long time. Since Spanish has no phonetic symbol, each Spanish letter has its corresponding pronunciation. Its stress is also regular. For example, words ending with vowels have a stress that is placed on the last but one syllable. Except that words ending with the consunants of $\mathrm{s}$ and $\mathrm{n}$ have a stress placed on the last but one syllable, all words ending with consonants have a stress placed on the last syllable. Compared with Spanish, Engilsh has irregular pronunciations. That is, its stress is not fixed and there are lots of silent English letters. Furthermore, these sound letters also have strong form and weak form. Thus, as for learners who have had certain English foundation, and especially beginners of Spanish, if they come to contact with Spanish, although they may feel that pronunciation of Spanish is relatively simple and regular, the negative influences as a result of differences between these two languages would usually disturb and thus affect the effect of Spanish learning.

\subsection{Transfer in terms of vocabulary}

There are a lot of transfers between English and Spanish in terms of vocabulary. The transfer here includes both positive transfer and negative transfer, but mostly positive transfer. "Positive transfer means that similarities between the mother tongue and the target language may facilitate the second language learning and accelerate certain development sequences of interlanguage". (Yu Liming, 2004) As for Spanish learners who have had certain English foundation, the positive transfer is mainly manifested in that English that has been grasped by the Spanish learners are able to help these learners apprehend and master certain language items in Spanish learning. Transfer between the two languages in terms of vocabulary is specifically reflected in the three aspects of word, phrase and idiomatic phrase.

\subsubsection{Transfer in words}

Quite a large number of vocabularies between the two languages have highly similar spelling, and here we only select several typical cases (See Table 1). As for Spanish beginners, although they have not learnt these words, they are totally able to guess the meanings of these Spanish words by referring to the English knowledge they have grasped. Furthermore, in terms of word patterns, both English and Spanish can be classified into simple words, derivative words and compound words, etc.

\section{Insert Table 1 Here}

\subsubsection{Transfer in phrases}

Some phrases in English and Spanish also have high similarity. For instance, la oveja negra in Spanish refers to "incompetent members (in a family or a group)", whereas the black sheep in English refers to "prodigal", but both these two phrases can be directly translated into “黑色的绵羊” in Chinese.

\subsubsection{Transfer in idiomatic phrases}

Affected by English, Spanish has high integration (mezcla) with English in terms of vocabulary, especially in 
idiomatic phrases. For example, Hasta luego in Spanish (good bye) is expressed as Te veo (namely, the corresponding English expression see you) by more and more people, which is called Spanglish. (Dong Yansheng \& Liu Jian, 2000)

Although these two languages have strong positive transfer in terms of vocabulary, learners have to make careful distinction between the two in their learning so as to avoid making confusions and to reduce negative transfer influences of English vocabulary upon learning of Spanish vocabulary. Some words have same or similar word patterns, but they have totally different meanings. For example, lecture in English means “讲座, 演讲”, whereas lectura in Spanish means “阅读, 读物”.

\subsection{Transfer in terms of grammar}

In terms of grammar, these two languages also have obvious positive transfer and negative transfer. Spanish has high similarity with English in levels of grammatical structure and parts of speech. For instance, these two languages are quite close to each other and even similar in terms of changes in active voice and passive voice of verbs, changes in comparison of adjectives, usage of pronouns, usage of past participles and adverbial verbs (equivalent to present participles in English) and constitution of subordinate clauses and infinitives, etc. Here, we only take usage of tense as the example to illustrate the phenomenon of positive transfer between English and Spanish. Tenses in Spanish can find their corresponding tenses in English (See Table 2).

\section{Insert Table 2 Here}

These corresponding tense also have high similarity in terms of structure. Let's take the present perfect tense of the two languages as the example:

Spanish: auxiliary haber + past participle;

English: auxiliary have (has)+ past participle.

Of course, English and Spanish also have great distinctions in terms of grammar. For instance, adjectives in Spanish are often placed after nouns to modify the nouns, whereas adjectives in English are usually placed before nouns to modify the nouns. Nouns in Spanish not only have changes of singular and plural forms, but also have changes in feminine and masculine. Furthermore, words used to modify nouns need to be consistent with the nouns they modify and define in terms of gender and number, such as, articles, adjectives and pronouns. In contrast, nouns in English only have changes of singular and plural forms, and qualifiers have no changes of feminine and masculine and number, such as, articles, adjectives and pronouns. This kind of negative transfer phenomenon usually causes students to make mistakes in learning of Spanish grammar as a result of the "stereotypical" influence that nouns in English only have changes in number.

\section{To use correctly influences of transfer of language between English and Spanish to effectively facilitate automatic learning ability of Spanish learners}

\subsection{Inscapes of automatic learning ability}

According to Littlewood, as for automatic learners, "the will of independent action of learners depends on their motivation and self-confidence and the ability of learners' independent learning rests with their knowledge and skills." (Littlewood, W., 1996) Dicknson said, automatic learning "was not only an attitude of learning, but also an ability to learn independently." Attitude is a kind of responsibility in which one makes a decision on his learning and ability is decision-making and reflection of the learning process. (Dicknson, L. \& A. wendn.(eds.), 1995) According to the viewpoint of Dickinson, the core of "automatic learning" is the ability of learners to be responsible for management of their learning, namely, the ability of students to make automatic control, adjust learning materials and information and return to repeated cognitive processing at any time when it is necessary so as to enable the learning process to transfer from the shot-term memory with limited capacity and time to the long-term memory with almost infinite capacity and time, in order to strengthen the efficacy of their learning. (Holec H., 1981)

As a sort of "independent learning ability", students' automatic learning ability refers to the sum of all sorts of psychological qualities to successfully complete an automatic learning task, which mainly includes self-orientation ability of automatic learning, ability to apply learning strategy, self-control ability and self-evaluation ability. (He Jisheng, 2009) According to the viewpoints of the above academics, we can further make an analysis of the inscapes of automatic learning ability, which include the first-class indexes and the second-class indexes, as is shown in Table 3.

\section{Insert Table 3 Here}




\subsection{Effective strategies to enhance the automatic learning ability of Spanish learners}

As for a large majority of Spanish learners who have already had certain English basis, we have to take effective measures from the two aspects of learners themselves and the classroom teaching of teachers in order to enhance in an overall way their automatic learning ability. In order to actually enter the process of automatic learning and gradually improve the automatic learning ability, in addition to their own conditions, foreign language learners also have to be directed by teachers with consciousness to facilitate them to internalize their automatic consciousness into strong desire to learn. (Jiang Qingxin, 2006)

\subsubsection{Spanish learners have to set up correct language learning concepts}

Wenden pointed out, the learning strategies employed by students are affected, to large extent, by their learning concepts. Thus, understanding of the learning concept is the foundation to understand the learning strategies of learners. A systematic understanding of learners' learning concepts and offer of correct direction will help learners to establish correct language learning concepts, improve their learning strategy, enhance their learning efficiency and enable them to gradually become "automatic language learners" in the real sense. (Horwitz E K., 1987) According to modern foreign language teaching theory, influences on foreign language acquisition process mainly include emotional factors, such as, interest, motive, anxiety, and so on, quality and quantity of input of authenticity, diversity and efficiency of the target language of learners, and strategy of learners. Since classroom is the occasion where communication between teachers and students mostly occurs, classroom teaching should pay special attention to influential factors of the above three aspects, namely, cultivation of students' interest, offer of appropriate language input, cultivation of students' learning strategy and offer of direction for students' extracurricular learning. (Shu Dingfang, 2004) Effective operation of classroom teaching functions can help learners establish correct Spanish learning concepts.

3.2.2 To strengthen comparison and summary of English and Spanish knowledge and to realize transfer of cognitive structure

According to Ausubel, what exerts influences upon new learning is not merely similarity between two learnings, but more importantly the cognitive structure variables that are stored in the long term memory of individuals (Ausubel, 1994). Cognitive structure transfer is a process in which the existing linguistic acquisition cognition is transferred to new learning through mediating variables, so as to improve the learning efficiency. Thus, in the process of Spanish learning, learners have to strengthen comparative learning between English and Spanish, pay attention to similarities and dissimilarities between the two languages in terms of pronunciation and intonation, morphological structure and usage of grammar, deepen comprehension of Spanish knowledge and give full play to the positive transfer influences of English upon Spanish. Simultaneously, learners also have to employ the method of induction to realize transfer of cognitive structure by means of inducing and summarizing content and influences of transfer between English and Spanish.

\subsubsection{To strengthen metacognitive training among learners with scientific methods}

Proposing any concept originates interactive experience of the cognitive subject and the realistic world, while language is the concentrated manifestation of this experience in different countries and different cultures. (Kuang Xinhua \& Meng Qian, 2009) Metacognition is cognition of cognition, specifically speaking, knowledge about the cognitive process of an individual and the ability to adjust these processes. It has two independent yet interrelated constituents, namely, metacognitive knowledge and metacognitive control. Dickenson emphasized, the linguistic consciousness of students and their linguistic learning consciousness were the necessary elements for effective metacognitive strategic guidance in the classroom (Dickson, L., 1992) The former one includes the ability to distinguish register and linguistic functions and specific linguistic skills, as well as the ability to deduce grammar and linguistic transfer. The latter includes self-consciousness, self-management, self-control and self-evaluation. Metacognitive transfer strategy requires teachers to take appropriate teaching means as the mediating variables in the process of teaching and to apply the metacognitive strategy employed in students' learning certain knowledge into other learning, with the aim of helping students enhance their automatic learning ability. In Spanish teaching, teachers may offer training of metacognitive learning strategies among students by the means of special lectures, etc, and combining students' mastery of Spanish. Usually, students are able to form a set of their own learning methods suitable for themselves after metacognitive training, which can effectively enhance their automatic learning ability.

\subsubsection{To create Spanish learning environment and to appropriately employ emotional strategies}

In the process of Spanish teaching, teachers may introduce multimedia, a sort of mediating variable that is able to create contexts of listening and speaking, to generate a language environment similar to the indigenous 
Spanish speaking countries and make students have the feeling of "personally on the scene" through the multiple sense organs functioning of language, image and sound together on students, so as to stimulate students' interest in learning Spanish and effectively enhance their efficiency in learning Spanish. Often, collision caused by differences between existing English knowledge and newly learned Spanish knowledge occurs among Spanish learners, which may cause students to fall into confusion, anxiety and uneasy emotion. According to Carl Rogers, the cognitive process of students and the emotional process are a unified process that is intertwined together. Those who place emphasis on the "informal course" of "emotional teaching" are able to fully develop students' internal driving force, which, in turn, may stimulate students to go towards success finally. (Liu Jie, 2010) Therefore, teachers should not monopolize the decision-making authority of students' learning, but ought to play the role of a counselor or a facilitator, (Hua Weifen, 2002) attempt to set up lively, relaxed and harmonious classroom environment and coordinate relations among students. For instance, they may change the traditional seats order of students into a U-pattern and place themselves in the middle of students. Both teachers and students are participators in the classroom, and there is no pure sitter-in. Besides, teachers should design more group cooperation practices and reduce the times for an individual answering question, which may greatly increase the opportunities for students to communicate in Spanish, reduce students' anxiety and overcome their negative emotions. Furthermore, usage of English with a definite purpose in a Spanish classroom can not only enable students to learn Spanish with more relaxation, faster speed and fewer mistakes, but can also help students cultivate the linguistic cognitive psychology, overcome students' psychology to fear the inability to learn Spanish well, and discover and grasp the rules of learning various languages through active and enthusiastic observation.

Transfer of language between English and Spanish in terms of content and forms of expression is various, and discussion about content transfer in this paper is just to throw out a minnow to catch a whale. How to employ the phenomenon of transfer between the two languages to improve the automatic learning ability of Spanish learners requires the learners themselves and teachers to continue to make explorations and conclusions in practice of "teaching" and "learning".

\section{References}

Ausubel. (1994). Education Psychology. Beijing: People's Education Press, 153.

Bußmann Hadumod. (2003). Dictionary of Linguistics. Beijing: The Commercial Press, 567.

Dicknson, L. \& A. wendn.(eds.). (1995).Special Issue: Autonomy. System, 23(2).

Dickson, L. (1992). Learning Autonomy 2: Learner Training for Language Learning. Dublin, Ireland: Authentic Language Learning Resources Ltd.

Dong, Yansheng \& Liu, Jian. (2000). Espanol Moderno, Volume 3. Beijing: Foreign Language Teaching and Research Press, 31.

He, Jisheng. (2009). Connotation, Formation and Dynamic Analysis of Students' Automatic Learning Ability. Educational Review, (2):82-83.

Holec H. (1981). Autonomy and Foreign Language Learning. Oxford: Pergamon.

Horwitz E K. (1987). Surveying student beliefs about language learning. In Wenden A, J Rugin. Learner Strategies in Language Learning. Hemel Hempstead: Prentice-Hall.

Hua, Weifen. (2002). On Learner Autonomy. Shenzhen University Journal, (Humanities \& Social Sciences), (2): 110 .

Jiang, Qingxin. (2006). Survey on Difficulties and Demands of Students' English Learning --- Enlightenment to Reform in College English Teaching. Sino-US English Teaching, (2):45.

Kuang, Xinhua \& Meng, Qian. (2009). On Role of Metacognition in Translations. Jiangxi Social Sciences, (12):209.

Littlewood, W. (1996). Autonomy in Communication and Learning in the Asian Context. In Proceeding of Autonomy 2000: the Development of Learner Independence in Language Learning, King Monglus't Institute of Technology Thonnburi, Bangkok.

Liu, Huashan \& Cheng, Gang. (2006). Higher Education Psychology. Hubei People's Press, 104.

Liu, Jie. (2010). Application of Emotional Strategy in Teaching of Spanish as a Second Foreign Language. Education for Chinese After-school, (1):67.

Odlin, T. (2001). Language Transfer-Cross-linguistic Influence in Language Learning. Shanghai: Shanghai 
Foreign Language Education Press, 209.

Shu, Dingfang. (2004). ELT in China: Problems and Solutions. Shanghai: Shanghai Foreign Language Education Press, 197.

Yu, Liming. (2004). Transfer and Second Language Acquisition-Review, Reflection and Research. Shanghai: Shanghai Foreign Language Education Press, 3, 5, 56.

Table 1. Contrast of transfer of words between English and Spanish

\begin{tabular}{|l|l|l|l|}
\hline English & Spanish & Part of speech & Chinese translation \\
\hline dictionary & diccionario & Noun & 字典 \\
\hline accompany & acompañar & Verb & 陪伴 \\
\hline possible & posible & Adjective & 可能 \\
\hline directly & directament & Adverb & 直接地 \\
\hline in & en & Preposition & 在...里 \\
\hline preoccupied & preocupado & Past participle & 心事重重的 \\
\hline
\end{tabular}

Table 2. Table of comparison between English and Spanish in terms of tense

\begin{tabular}{|l|l|}
\hline \multicolumn{1}{|c|}{ Spanish } & \multicolumn{1}{c|}{ English } \\
\hline Narrative present tense & The simple present tense \\
\hline Narrative simple past tense & The simple past tense \\
\hline Narrative past imperfect tense & The simple past tense and past continuous tense \\
\hline Narrative future imperfect tense & The simple future tense \\
\hline Narrative present imperfect tense & Present perfect tense \\
\hline Narrative past perfect tense & Past perfect tense \\
\hline Narrative future perfect tense & Future perfect tense \\
\hline conditional tense (Conditional) & Past future tense \\
\hline
\end{tabular}

Table 3. Constitution of elements in automatic learning ability

\begin{tabular}{|c|l|}
\hline First-class indexes & \multicolumn{1}{|c|}{ Second-class indexes } \\
\hline Self-orientation ability & $\begin{array}{l}\text { Target positioning ability, plan formulation ability and target } \\
\text { implementation ability }\end{array}$ \\
\hline Self-learning ability & $\begin{array}{l}\text { Information absorption ability, knowledge integration ability and } \\
\text { team learning ability }\end{array}$ \\
\hline Self-control ability & $\begin{array}{l}\text { Information feedback ability, target control ability and } \\
\text { environment coordination ability }\end{array}$ \\
\hline Self-evaluation ability & $\begin{array}{l}\text { Self-reflection ability, comparison and contrast ability and stable } \\
\text { improvement ability }\end{array}$ \\
\hline
\end{tabular}

